\title{
The measurement and reduction of urban litter entering storm- water drainage systems: Paper 2 - Strategies for reducing the litter in the stormwater drainage systems
}

\author{
Mark Marais ${ }^{1}$ and Neil Armitage ${ }^{2^{\star}}$ \\ ${ }^{1}$ Formerly Department of Civil Engineering, University of Cape Town, now independent consultant \\ ${ }^{2}$ Department of Civil Engineering, University of Cape Town, Private Bag, Rondebosch 7701, South Africa
}

\begin{abstract}
A previous South African study looked at the removal of litter from the drainage systems once it was already there. Yet the litter problem cannot be addressed in an effective and sustainable manner without an effective integrated catchmentwide litter management strategy. This strategy should include planning controls, source controls, and structural controls. The main focus of this paper is the source control of urban litter. It reviews international and local practice, and reports on the results of a two-year monitoring programme conducted in nine pilot catchments covering a range of different land uses, socio-economic levels and population densities in the City of Cape Town. It proposes preliminary guidelines for the reduction of urban litter loads entering the drainage system by dealing with litter pollution at its source.
\end{abstract}

Keywords: litter management, stormwater drainage systems, water quality management, source controls, reduction of urban litter, solid waste pollution control

\section{Introduction}

Few South Africans can have failed to notice the unsightly and often malodorous rafts of rubbish floating down our urban watercourses, and the ribbons of litter lining their banks. While the impact of litter pollution of urban stormwater runoff may appear to be mainly of visual and aesthetic importance, litter also seriously interferes with aquatic life in the receiving streams, rivers, lakes and oceans (Victoria Stormwater Committee, 1999).

Since the 1970s, littering has been considered a social behavioural and educational problem (Andres, 1993). As Senior (1992) comments: "it is not just the nature of the items themselves, nor the demands of retailers and manufacturers which are to blame, it is the community, whose behaviour, attitude and awareness are fundamental to the problem.” The proliferation of litter is intensified by rapid urban growth, increasing mobility, and improper disposal habits (National Center for Environmental Decision-making Research, 1999).

A more sinister aspect of the presence of litter is that it is one of several environmental cues associated with neighbourhood decline. Litter is a physical "symbol of disorder” or “incivility” along with vandalism, dilapidated or abandoned housing, and dirty vacant lots (Florida Center for Solid and Hazardous Waste Management, 1998). Skogan (1990) in fact found that people identify the incidence of crime with environmental cues. His research indicated that physical and social disorder correlate very strongly. American researchers have even gone so far as to hypothesise that crime may bereduced by improving a neighbourhood's environment(DeFrances and Titus, 1994). In South Africa many environmentally degraded areas are subject to gangsterism and rampant crime. It would be too simplistic to blame this on excessive littering, but it certainly may be a factor in perpetuating an atmosphere of lawlessness.

\footnotetext{
* To whom all correspondence should be addressed.

要+2721 650-2589 fax:+2721 689-7471;

e-mail: armitage@ebe.uct.ac.za

Received 30 April 2004; accepted in revised form 31 August 2004.
}

A previous South African study concentrated on the removal of urban litter (here defined as urban solid waste lying in the public domain) from the stormwater systems once it was already there (Armitage et al., 1998; Armitage \& Rooseboom, 2000a; b; c). One of the conclusions of this investigation was that this was addressing the symptoms of the problem rather than the cause. It was also important to consider reducing the amount of litter entering the drainage systems in the first place. In reality, the litter problem cannot be addressed in an effective and sustainable manner without the implementation of effective integrated catchment-wide litter management strategies. These strategies could include planning controls (adopting land- use policies which restrict the situation of litter-producing activities to areas where it is possible to contain and control litter accumulation), source controls (reducing litter loads entering the drainage system by dealing with solid waste at source) and structural controls (removal of urban litter from the drainage systems at specially engineered structures).

This paper focuses primarily on the source control of urban litter. It reviews international and local practice, and reports on the results of a two-year monitoring programme conducted in nine pilot catchments covering a range of different land uses, socio-economic levels and population densities in the City of Cape Town, South Africa (hereinafter called simply “Cape Town”). The paper proposes preliminary guidelines for the reduction of urban litter loads entering the drainage system by dealing with litter pollution at its source. It should be emphasised that the findings and the guidelines are largely based on Cape Town experience and that their applicability to the country as a whole has not been established. However, since the challenges are similar, it is likely that many of the findings will be equally applicable to the other urban areas of South Africa.

\section{The development of integrated catchment litter management strategies}

The basic assumption underpinning this study was that, for there to be effective reduction of urban litter in the drainage system, 

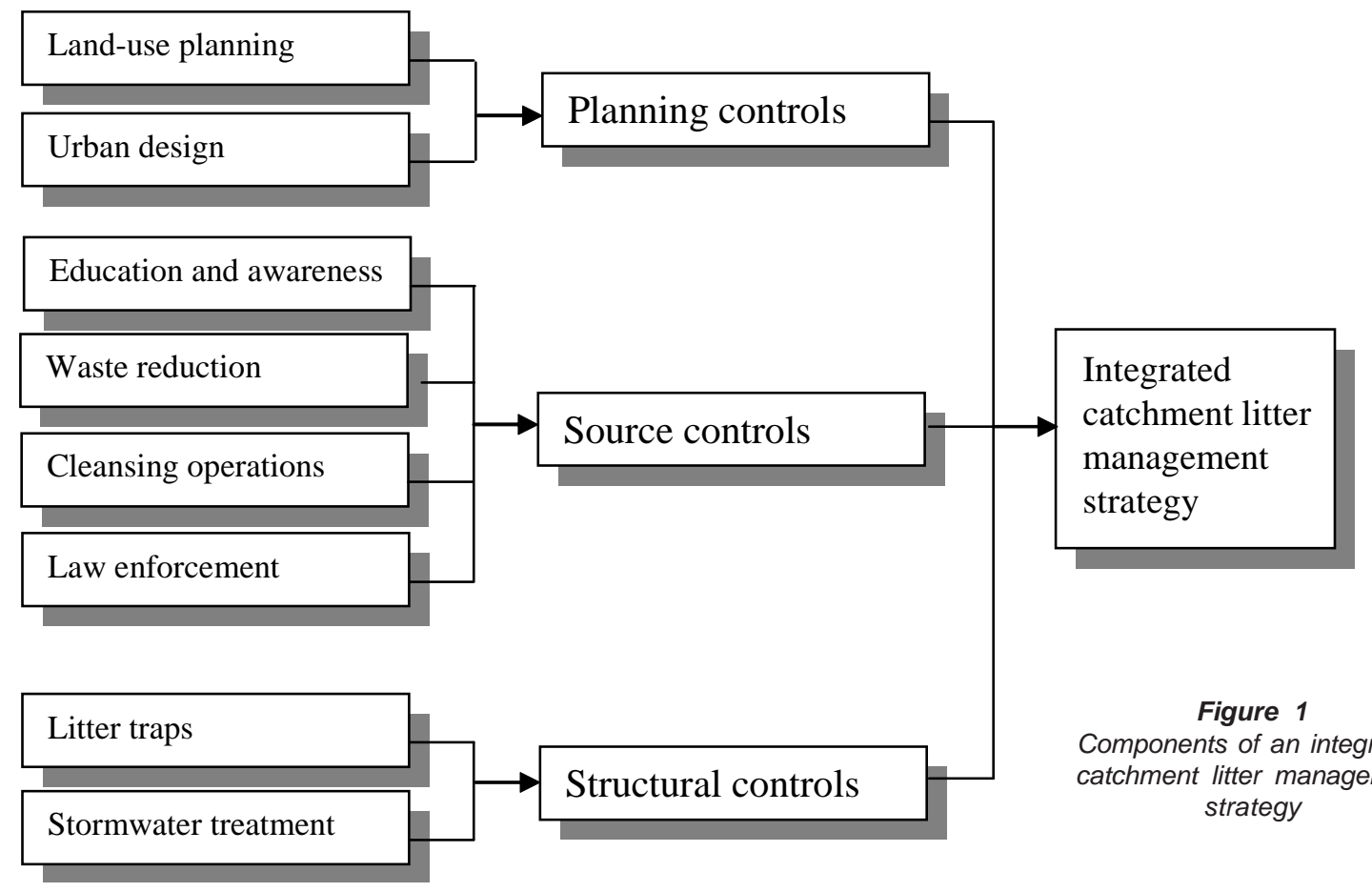

Figure 1

Components of an integrated catchment litter management strategy

consideration must be given to the whole drainage catchment. Furthermore, since it is highly unlikely that the problem will be addressed by a single intervention, it is generally necessary to consider the implementation of a suite of measures in an integrated manner. The optimal choice of measures is, however, likely to vary from one catchment (or subcatchment) to the next as conditions change. What is thus required are a set of integrated catchment-wide (or simply “catchment”) litter management strategies. Each catchment should have its own catchment litter management strategy, which may be different from neighbouring catchments. The individual strategies would generally be evaluated on the basis of costeffectiveness (cost of measures in relation to reducing risk), capability (capacity of the local authority or community in terms of sufficient resources, expertise or powers to implement them) and opportunity (there may, for example, be practical restraints preventing a trap from being installed at a particular location) (Victoria Stormwater Committee, 1999).

An integrated catchment litter management strategy would typically involve three types of operations; planning controls, source controls, and structural controls (Fig. 1).

Planning controls are aimed at adopting land-use policies which preserve existing valuable elements of the drainage system, such as natural channels, wetlands and riparian vegetation, by restricting the use of such areas. They also seek to minimise the risk of litter reaching the drainage system by situating litter-producing activities in areas where it is possible to contain and control litter accumulation more easily. Requiring the submission of acceptable pollution control measures as part of any development application is an example of a planning control (Canterbury Urban Runoff Taskforce, 1990). Clearly, any approval should be linked to the guarantee that there will be ongoing monitoring of pollution levels at agreed points with penalties for non-compliance. Another example of a planning control is the use of swales - essentially grass-lined, shallow, wide ditches - as a primary drainage element wherever possible. Swales have the ability to trap litter and contaminants such as heavy metals, oil and grease before they reach the stormwater system. Their chief disadvantages are the extra space that they occupy, and the need to maintain the grass.
Source controls are aimed at reducing the litter loads entering the drainage system by dealing with waste at source. These are the focus of this paper and will be described in greater detail below. They typically involve ongoing education campaigns to ensure that the public is well informed, waste reduction, cleansing operations, and law enforcement.

Structural controls are aimed at intercepting or removing solid waste after it has entered the drainage system by installing structures such as traps, nets or diversion systems in the stormwater system. As previously mentioned, these were the focus of an earlier study (Armitage etal., 1998; Armitage \& Rooseboom, 2000a; b; c). In some instances, it may be possible to divert the most polluted portion of the stormwater to wastewater treatment works where, inter alia, the urban litter can be removed. This is commonly done in countries that have combined sewers where low stormflow is added to the sewage. Unfortunately this practice gives rise to major problems during periods of high flow where the contents of the sewers, including sewage, overflow into neighbouring watercourses.

\section{Source controls}

There are four main categories of source controls; educational campaigns to bring about greater public awareness and response to the litter problem, waste reduction to reduce the generation of urban waste, cleansing operations to prevent urban waste from getting into the environment, and law enforcement to ensure compliance.

\section{Educational campaigns}

Education is an essential component of an integrated catchment management strategy. Its purpose is to inform and motivate the public including those in commerce and industry, local government, and law enforcement. The public is told about the interconnection between the streets, stormwater drainage system, rivers and oceans, and how daily activities affect stormwater quality (Victoria Stormwater Committee, 1999). The rationale behind these educational campaigns is that it is "a better investment to educate litterers 
out of their habit than to go around just picking up after them" (Florida Center for Solid And Hazardous Waste Management, 1998). At present there is an enormous interest world-wide in the development of effective educational litter campaigns as can be readily established through a search of the Internet.

Educational programmes have to be tailored to the particular target group in a catchment. Some options include:

- Clean-up campaigns are particularly appropriate for schoolchildren where the co-operation of the local schools can be obtained. If those involved are paid, it may also be useful in reaching adults in areas with high unemployment. By way of example, 3644 volunteers took part in the 1998 clean-up in the Western Cape filling 10624 bags from $374 \mathrm{~km}$ of beaches with an estimated mass of $30726 \mathrm{~kg}$ (Cape Metropolitan Council, 1999). Note that clean-up campaigns are primarily educational in nature. As a form of litter reduction they are generally unsustainable. It is important to ensure that all people involved in clean-up campaigns are properly protected against exposure to sharp objects and pathogenic organisms. As a minimum, this means that everyone should be equipped with gloves.

- Providing litter receptacles on buses and taxis and staffing them with volunteers to educate the public about proper waste disposal is a method that has been used with some success overseas (Florida Center for Solid and Hazardous Waste Management, 1998). It is most likely to be successful in those areas where there are large numbers of commuters who use public transport. In South Africa this method is unlikely to reach middle-and high-income citizens who do not generally make use of public transport.

- Highway billboards containing anti-litter messages have the most impact on highly trafficked routes where they enjoy maximum visibility (Florida Center for Solid and Hazardous Waste Management, 1998). There may be objections to them in residential areas.

- Educational material could be supplied to ratepayers with the rates accounts in middle- and upper-income residential areas (Canterbury Urban Runoff Taskforce, 1990). In commercial and industrial districts they would, however, be read by a very small fraction of the people who actually spend time there. In informal settlements, many residents are not ratepayers and there may also be problems with low literacy levels.

- Painting anti-littering messages on catch-pit covers encouraging residents not to litter and informing them where the litter ends up may be a successful strategy in areas where much of the littering is from pedestrians e.g. low-income areas and commercial and industrial districts (Canterbury Urban Runoff Taskforce, 1990). The idea is to educate citizens about the direct connections between storm drains and waterways. Whether people read messages that are at ground level or underfoot needs to be investigated.

- Xeriscaping seeks to discourage littering through beautification using landscaping practices that benefit the environment (Florida Center for Solid and Hazardous Waste Management, 1998).

- The mass media, including radio, television, videos, newspapers, magazines etc. can be a powerful medium for conveying messages about litter management providing that the message is presented in such a way that it catches and holds the viewer's/ reader's attention.

- An example of a particularly innovative educational campaign is to be seen at the Two Oceans Aquarium in Cape Town where a strong environmental message, including anti-littering, is conveyed to children using a puppet show.

\section{Waste reduction}

Commerce and industry are the ultimate source of most of the litter, if not directly, then indirectly through the products that they sell and, in particular, the packaging that the products are wrapped in. It therefore makes a lot of sense to work closely with business to determine the nature and extent of those activities likely to generate litter that might reach the stormwater system. If it can be shown that, e.g. the packaging of a particular product adds significantly to the litter stream, it may be possible to persuade businesses to change their packaging to more environmentally friendly options or reduce its bulk by taxing them for packaging that is not biodegradable or recyclable. On the other hand, if it can be shown that a particular type of container is a major component of the litter stream, businesses could be pressured into using recyclable containers by imposing levies on containers that are not recyclable and by offering incentives such as deposits for the return of recyclable containers. Ultimately, manufacturers need to be persuaded to consider the environmental impact of their products "from the cradle to the grave”. Specific options include:

- Levy pollution taxes on items that are considered likely to be major contributors to the litter stream. The potential effectiveness of this strategy would have to be determined from an analysis of the litter composition in a catchment. The advantage is that the taxes would be relatively easy to administer, serve as incentives to manufacturers and retailers to change to recyclable containers or packaging which are not taxed, and provide revenue to pay for its administration. The New Jersey Clean Communities Act of 1986 is funded by a tax on items determined to be most likely to become litter (Florida Center for Solid and Hazardous Waste Management, 1998). Manufacturers pay 1\% of sales of these items within New Jersey. Retailers with annual in-state sales of more than $\$ 250000$ pay $0.000225 \%$, whilst retailers whose annual sales are under \$250 000 are exempt.

- Charge a deposit for containers. In New York, the Returnable Container Law of 1982 enforces a deposit of at least 5 c on beer, soft-drink, wine-cooler, mineral and soda-water containers (Florida Center for Solid and Hazardous Waste Management, 1998). A $1.5 \%$ handling fee is paid by the distributor to the dealer or operator. The redemption rate was about $76 \%$ in 1996 . In South Africa, deposits are charged on some, but not all, bottles, and latterly on polyethylene shopping bags. This needs to be extended to other containers.

- Consumers should also be persuaded to minimise their waste through reduction in the use of non-biodegradable products or packaging, the reuse of items, e.g. plastic bags, wherever possible, and the recycling of as much as possible. It is important to realise that recycling is something that requires a fair degree of commitment from the general public to work successfully. The extent to which separation is required must not be too ambitious. Most consumers have great difficulty, for example, in deciding which plastics are recyclable. Schemes which require the separation of easily differentiable items only, such as tins and glass bottles, have been successful though and are certainly worthy of general implementation. This measure has particular potential where separation of litter can provide an income to jobless people provided that the portion of the litter for which they cannot gain any income is not discarded but properly disposed of (Pressend, 1998). A relatively compact, high-density residential area with high rates of unemployment is a candidate for such a measure. An example of a successful South African recycling campaign is “Collect-a-Can”. In 1999, 
by enlisting the help of communities, some 40000 collectors recovered $63 \%$ of all used beverage cans, selling them to Collect-a-Can's depots and making the can the most recycled sweeping packaging in Africa (Institution of Municipal Engineering in Southern Africa, 2000).

- It is important that, wherever possible, developers should be forced to develop and implement waste management plans that will help to prevent contaminant spills and construction rubble from reaching the drainage system. The impact of construction activity on the drainage system is often particularly acute in the vicinity of informal settlements that are characterised by ongoing informal construction that not only generate large quantities of rubble, but may also result in the destabilisation of the ground cover leading to soil erosion and the consequential silting of drainage structures. In such areas it is difficult to insist on site management plans from the builders and even more difficult to police them, but the builders should be encouraged to act in a responsible manner.

\section{Cleansing operations}

Cleansing operations concern the removal of the waste that is generated. Preferably this should be at the source, but failing this, it should be as close to the source as possible. Once urban litter gets into the broader environment, it becomes difficult and expensive to collect and rapidly becomes a nuisance. Some options include:

- Refuse removal. There is universal agreement that the most effective way to reduce litter is an effective refuse removal service. Unfortunately many South African local authorities claim that they do not have the resources to implement proper refuse removal or to increase the frequency of their litter collections when desirable. Nevertheless, it might be possible to redistribute the collection effort based on an analysis of where the greatest needs are without increasing the resources needed to do so. Imposing waste charges on businesses could finance additional litter collections (Florida Center for Solid and Hazardous Waste Management, 1998).

- Placing of communal collection depots to concentrate litter. In some localities, where a door- to -door refuse removal service is not viable, it may be possible to get the community to bring their litter to well-positioned communal depots where the volume could be reduced by the removal of the recyclable and biodegradable materials. The local authority would then collect the residue from these depots. Some of the savings realised in the collection and transport costs of the local authority could be added to the return on the recyclable materials to provide an income in areas with high unemployment(Pressend, 1998).

- Better placement and design of litter bins. There is general agreement that poorly designed litter bins that are susceptible to vandalism, or allow the wind or scavenging animals to remove litter from the bin should be avoided. Cape Town, inter alia, has looked at alternative designs that will overcome these problems. Interestingly enough though, studies undertaken in Melbourne, Australia have shown that providing additional litter bins does not necessarily reduce the amount of litter reaching the stormwater system (Australian Bureau of Statistics, 1999). People who are environmentally aware will carry their litter

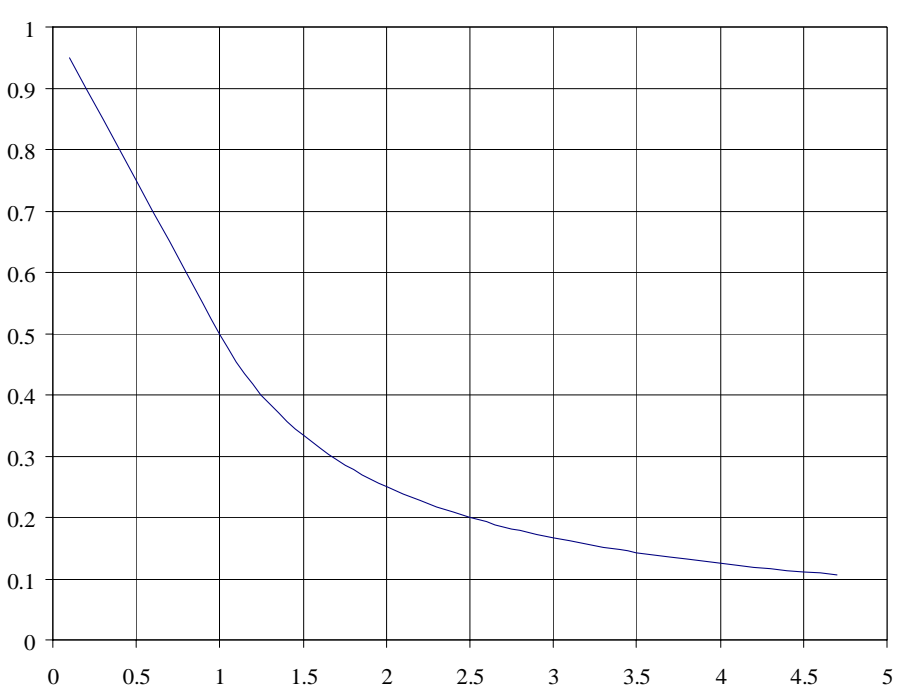

Average number of days between street sweeping / average number of days between significant storms

Figure 2

Maximum expected efficiency of street sweeping (Armitage, 2001)

with them, even if it is a fairly long distance, until they find a litter bin in which to deposit it. However, it is also clear that, in South Africa at least, litter bins need to be located at an appropriate density in areas with high levels of pedestrian traffic.

- “Adopt-a-block” programmes are good candidates for commercial and industrial areas where businesses can be persuaded to assist in the clean-up of the area by virtue of the favourable publicity and increased customer base this will garner (Florida Center for Solid and Hazardous Waste Management, 1998). The approach could also be adopted in residential areas by getting the local communities involved. An extension of this idea is to encourage "Friends of the..." type organisations where a group of like-minded volunteers "adopt” a mountain, stream or park in order to protect it.

- Street sweeping. Frequent (typically daily) street sweeping can remove more than $98 \%$ of the urban litter on the street (Armitage, 2001). Note that once the frequency of the street sweeping drops below that of the significant rainfall events, it intercepts less than half of the litter deposited in the streets. Figure 2 shows the predicted removal efficiency of street sweeping based on the ratio of average days between streetsweeping to average days between significant rainfall events (from about $10 \mathrm{~mm}$ upwards). If this ratio varies significantly from season to season, separate estimations need to be made for each season. It makes the assumptions that street sweeping is able to remove all the litter off the road; that the significant rainfall events are large enough to mobilise all the litter remaining on the road; and that the catch-pits have large enough openings to accommodate the largest pieces of litter. In reality, some litter will be inaccessible (e.g. "hidden” under motor vehicles), few rainfall events are large enough to carry every piece of litter to the catch-pits, and the litter frequently accumulates at the catchpits without falling into them even if the opening is nominally large enough. It is easy to overestimate the efficiency of street sweeping. Since street sweeping is a relatively expensive operation, to be cost-effective it needs to be limited to areas where the litter loadings are particularly high, generally the commercial 
districts. It is also important to ensure that the litter is not being swept into catch-pits rather than being picked up and carted away.

\section{Enforcement options}

It is hard to persuade people to change the habits of a life-time without some form of enforcement. It is of concern that although existing South African bylaws do provide some control and protection against littering, there are seldom enough staff to enforce them, and whatever action is taken must of necessity be reactive since the pollution has already occurred. Unfortunately the police and local authorities often have more pressing demands than the enforcement of anti-litter legislation. Nevertheless, without effective enforcement, any litter management strategy is likely to fail. Options include (Florida Center for Solid and Hazardous Waste Management, 1998):

- Increasing the number of personnel enforcing anti-litter legislation through the use of volunteers. Volunteer litter patrol officers, preferably drawn from the local community and integrated with Neighbourhood Watch Programmes, could most effectively be instituted in residential areas. Anecdotal evidence suggests that littering is most easily controlled where the local communities take responsibility for keeping their neighbourhoods clean. "Trash troopers" is an example of a programme that co-ordinates volunteer litter patrol officers in Florida, USA.

- The publication of "pollution hot-lines" to assist members of the public in calling the authorities' attention to littering. A high degree of civic responsibility and environmental concern is required for the success of this strategy. Reasonably rapid access to a telephone is also necessary if offenders are to be successfully apprehended. An example of such a programme is “Don’t be a litterbug” in Pennsylvania, USA. Public service announcements are made explaining how litter affects the environment, and listing a toll-free hotline that anyone can call to report the sighting of someone littering. A letter is sent to the litterer explaining the effects of litter on the local economy together with a litter bag for the car.

\section{Examples of recent litter management strategies in South Africa}

In South Africa, the fundamental environmental rights and requirements guaranteed by the South African Constitution (South Africa, 1996) have given rise to a hierarchical suite of environmental legislation and associated policies at national and local level. Any approach to water quality management must promote integrated management and be conducive to sustainable development (Van Wyk et al., 2002). Specifically, the National White Paper on Integrated Pollution and Waste Management for South Africa (2000) includes an outline of the government's strategic goals and supporting objectives for addressing the major issues regarding pollution and waste, as well as for measuring the success of policy implementation. Integrated pollution and waste management is defined as a holistic and integrated system and the process of management aimed at (City of Cape Town, 2000):

- Pollution prevention and minimisation at source

- Managing the impact of pollution and waste on the receiving environment

- Remediating damaged environments

At the local level, by way of example, Cape Town has approved an Integrated Metropolitan Environmental Policy (IMEP) as the first environmental policy for the city. The IMEP is a set of principles and ethics that sets the framework for environmental management in the City. "Litter" is one of the six sectoral approaches that have been identified as priorities under the IMEP. One of the key priorities for the first implementation of this policy is a programme to eliminate litter and illegal dumping (Fairest Cape Association, 2002a).

Backed by the promulgation of the aforementioned enabling legislation and its associated policies at both national and local level, several initiatives have contributed, or are contributing valuable information on the effectiveness of various litter management strategies in reducing the volumes of litter entering South African stormwater systems. These include:

\section{The Dense Settlements Project}

The Department of Water Affairs and Forestry (DWAF) developed a National Strategy for Managing the Water Quality Effects of Densely Populated Settlements in co-operation with the Danish Cooperation for Environment and Development (DANCED) which culminated in the production of a series of five documents in June 1999 (DWAF, 1999a to e). The implementation guidelines, included in these documents, emphasised that effective solid waste management was critical to the implementation of the National Strategy both in terms of controlling the contamination of local water resources with litter, and to ensure the effective functioning of stormwater drainage systems (DWAF, 1999b). A key observation was that the costs of waste management should not be considered in isolation as the pilot studies revealed a strong link between filthy, unhygienic conditions and epidemiology or environmental health issues (Hinsch, 2000).

\section{The Mess Action Campaign of the City of Cape Town}

The Mess Action Campaign (MAC), which commenced in 2000, was a Cape Town initiative to address the unacceptable amount of litter and illegal dumping within the Unicity. MAC recognised that the causes of the littering and illegal dumping needed to be addressed, and thus a wide range of awareness and education programmes were implemented in schools, communities, businesses and various other institutions, to support the operational aspect and enforcement of littering and illegal dumping (Fairest Cape Association, 2002a). The first phase of this campaign, the "Waste Wise" mass community education campaign commenced in April 2002 with advertisements on local radio stations, in community newspapers, and on billboards and bins on the topics of littering and illegal dumping in English, Afrikaans and Xhosa (Liebenberg and Stander, 2002). The programmes also included an arts festival and drama competition in schools; the greening of schools; the linking of a primary school to a wetland; tackling the problem of getting refuse from informal settlements to collection points accessible by refuse removal vehicles; and the installation of bins along main routes in the high-density Cape Town township of Khayelitsha.

\section{Fairest Cape Association initiatives}

The mission of the Fairest Cape Association of Cape Town is "to promote a cleaner, healthier environment by enabling people to take responsibility for waste" (Fairest Cape Association, 2002b). The five aims of the organisation are:

- To increase awareness that waste is a resource

- To facilitate the development of systems to recover and add value to this resource 
- To make people aware of the volumes and nature of waste generated and their impact on the environment

- To enable groups to develop appropriate waste management options in partnership with local authorities

- To influence the development of policy and legislation on waste

The Association works closely with the Waste Departments of the City of Cape Town and regularly presents the "Principles of Solid Waste Management Planning Training Course” to participants from the City and DWAF. This course is designed primarily to assist those local government officials who are responsible for solid waste management, to plan and implement more holistic solid waste management programmes in their communities or cities.

During 1999, the Fairest Cape Association held workshops at 27 schools in the City of Cape Town as part of the "Wise up on Waste!” programme. The number of schools participating in litter recovery projects increased to 134 in 2000 with an additional 20 crèches and community organisations also involved. Other educational and training activities carried out by the Fairest Cape Association in 2000 included (City of Cape Town, 2000):

- The hosting of the Dentyne High Schools’ Environmental Quiz

- The holding of a number of teacher training workshops

- The successful launching of the Engen "Wise up on Waste!" Teacher Training Project

- The Millennium Mural Competition which depicted the impact of water and waste on catchments

- The Imizamo Yethu Community Programme in Hout Bay, Cape Town

\section{Waste minimisation clubs}

Between 1998 and 2000, with funding from the Water Research Commission (WRC), the Pollution Research Group at the University of Natal (now the University of KwaZulu-Natal) established pilot waste minimisation clubs to determine the feasibility of this approach in promoting waste minimisation to industry in South Africa (Barclay, 2002). Waste minimisation can be defined as the application of a systematic approach to reducing waste at source. It relates to all inputs and outputs from an industry, business site or process including water, energy, chemicals, raw materials, effluent, air emissions and solid waste. A waste minimisation club is a group of companies working together to reduce waste and save money and may be from the same or different industrial sectors. The club members meet regularly to exchange information and ideas on waste minimisation and to receive training in aspects of waste minimisation. The aim is to maximise the conversion of the inputs to the products whilst minimising the discharge of waste to water, air and land. This results in improved process efficiency and reduced emissions to the environment, translating into financial savings. As much as $50 \%$ of solid waste disposal can be saved through implementing waste minimisation (Barclay, 2002).

Initially, two pilot clubs, the Metal Finishing Waste Minimisation Club in the Durban region and a cross-sectoral club in the Hammarsdale area of KwaZulu-Natal were established. As of March 2002 there were 17 waste minimisation clubs running in South Africa with a further six in the planning stage (Barclay, 2002).

\section{Factors to be considered in the selection of litter management options}

Litter data obtained in the course of a two-year monitoring programme conducted in nine pilot catchments covering a range of different land uses and socio-economic levels in Cape Town(Marais and Armitage, 2003) show that the litter loads and profiles for residential, commercial and industrial areas are significantly different from one another. Litter loads in middle- and high-income residential areas, which are dominated by the contribution made by garden refuse, are lower than in low-income residential, commercial or industrial areas. In industrial areas, rubble and large items are significant contributors to the waste stream. Informal residential areas are characterised by ongoing informal construction activities that generate rubble and destabilise the soil leading to erosion and the consequential silting of catch-pits. Plastics are a significant contributor to litter loads for all urban land use types.

The main factors influencing the selection of litter management options are as follows:

\section{The composition of the litter}

The composition of the litter determines the method of control. Important questions are:

- Is the litter dominated by stone or rubble?

- Does packaging constitute a significant proportion of the litter and does it come from a particular business? It is important that significant litter sources be identified and the litter removed as close to the source as possible - before it has an opportunity to mix with different types of litter and become difficult to collect and separate.

- How much of the litter is composed of recyclable materials (such as glass bottles, cans and plastic containers)?

- Is there a significant proportion of garden refuse?

- Do entrained sediments add appreciably to the mass of the litter?

- Is there evidence of contamination by heavy metals?

- Are oil and grease spills evident?

\section{The volume of litter}

The volume of litter generated has a direct bearing on selecting the most appropriate litter management option. If only small volumes find their way into the stormwater system it is difficult to justify street sweeping, whilst installing well-situated and designed litter bins may prove cost-effective.

\section{The presence of a street-sweeping service}

Where street sweeping is infrequent or non-existent it may be inappropriate to introduce methods such as the installation of grates across catch-pit entrances that trap litter in the roadway. A study could, however, be undertaken to identify areas with high rates of litter accumulation and sweeping times and resources reallocated accordingly.

\section{The nature of the refuse removal service}

The nature of the existing refuse removal service is important because there is a clear link between service levels and litter loadings. Low-income areas often receive inferior refuse removal services which result in higher litter loadings in the stormwater system. If skips are provided for centralised refuse disposal, aspects such as the maximum walking distance, and ensuring that children are able to reach the top of the skip with their rubbish, are critical to their effectiveness. 
In residential areas, the nature of the land tenure is an important determinant of the community's sense of ownership and responsibility for their surroundings. Where this sense of ownership is lacking it is extremely difficult to motivate the community to change their littering behaviour, for example, through educational programmes.

\section{The composition of the community}

The size of the community that it is intended to reach will determine whether mass media such as newspapers, radio and television should be employed or whether it is feasible to train educators to engage directly with the community. If there are large numbers of children, programmes to promote environmental awareness, discourage littering and encourage recycling, etc. can be effectively propagated through the schools. Where there are large numbers of unemployed in the community, community-based litter collection and recycling initiatives can provide an income.

\section{The pedestrian volumes}

Routes which carry large pedestrian volumes generally have higher litter loads than those that are less trafficked. The provision of frequently cleared litter bins along these busy routes can be an effective way of reducing the quantity of litter reaching the stormwater drainage system. Billboards erected along these routes, with messages encouraging proper disposal of litter or recycling, can be expected to reach a large number of people whereas they would clearly have a marginal impact on the community if erected in areas with low pedestrian traffic.

\section{Community awareness of litter and the environment}

Where there is already a good understanding of the environmental problems caused by littering and the need to reduce the quantities, recycling programmes can be effectively implemented. If this understanding does not exist, an awareness programme would first have to be undertaken before recycling programmes could be considered. These should be orientated at both adults and school children (the latter being reached most effectively through compulsory topics in the school curricula).

\section{The urban layout}

The urban layout often dictates which particular options are possible. Important considerations are:

- Are there generous road reserves which permit the creation of swales to trap litter and contaminants such as heavy metals, oil and grease before they reach the stormwater system?

- Is there access to every dwelling for refuse removal trucks or is it necessary for litter to be brought to central collection areas?

- Are road verges surfaced or not (unsurfaced verges are vulnerable to erosion resulting in high silt loads)?

- Are the dwellings informal or formal (informal areas often generate more rubble because of ongoing building activity)?

\section{Evaluating various litter management options}

Various litter management options were implemented and monitored in several pilot catchments in Cape Town during the periods January to September 2000, and February 2001 to January 2002.

\begin{tabular}{|l|r|}
\hline \multicolumn{2}{|c|}{ TABLE1 } \\
Cost (2001 prices) per kg reduction in litter load \\
(rounded) in this study \\
\hline Litter management option & Cost per kg \\
\hline More frequent collections of litter & R140 \\
- Residential areas & R10 \\
- Commercial areas & R12 \\
Street sweeping & R5 \\
Emptying of catchpits & R14 to R20 \\
Installation of grates over catchpit entrances & $<$ R330 \\
Community education programmes & \\
\hline
\end{tabular}

The measured reduction in litter volumes were then used to estimate the cost in $\mathrm{R} / \mathrm{kg}$ reduction in litter reaching the stormwater system. All costs are calculated on, or have been adjusted to, 2001 figures and are expressed without VAT (Table 1). The various options are described in more detail below.

\section{More frequent collections of litter}

The most effective way to prevent litter finding its way into the stormwater system is to provide a frequent litter collection service which obviates the tendency for it to be illegally disposed of in public spaces such as roadways. R33 per bin per month was charged for refuse removal in Cape Town in 2001. Based on an average litter mass of $15 \mathrm{~kg}$ and four collections per month this works out at 55c/ $\mathrm{kg}$. From the litter profiles for residential areas obtained during the study, it is estimated that between 0 and $0.4 \%$ of household refuse generated finds its way into the stormwater system. Assuming that an additional $250 \mathrm{~kg}$ of refuse needs to be collected to realise a $1 \mathrm{~kg}$ reduction in the litter reaching the stormwater system, the effective cost of realising this reduction was then of the order of R137.50/kg in residential areas. However, based on litter data gathered in the Cape Town CBD in 2001, only an additional 18kg of refuse needs to be collected to effect a $1 \mathrm{~kg}$ reduction in the mass entering stormwater systems in commercial areas. The cost in realising a reduction in commercial areas was thus estimated to be R9.90/kg.

\section{Street sweeping}

Street sweeping is an extremely effective option where there are large litter loads generated within a manageable area (for example the streets of the CBDs, open-air markets and taxi and bus stations). In the Cape Town CBD, the cost of providing a street-sweeping service was estimated at R11.56/kg in 2001. The street sweeping is carried out two to three times during weekdays. In the morning and afternoon, the streets are swept by hand into bags that are then removed by vehicle. In the vicinity of restaurants and night clubs and other areas that have large numbers of people after working hours, the streets are swept mechanically in the late evening / early morning after most people have gone home. The combination of manual and mechanical sweeping methods affords the best opportunity to remove all the litter including that trapped between motor vehicles, and motor vehicles and the kerb.

\section{Cleaning of catch-pits}

Data from the Cape Town CBD indicate that cleaning catch-pits and linking pipes becomes economically worthwhile when the catchpits are greater than $46 \%$ full on average. The cost was estimated 
at R4.64/kg based on 2001 contract costs. Note that, whilst this option is financially attractive, large quantities of litter are inevitably lost downstream.

\section{Installation of gratings over catch-pit entrances}

For the installation of gratings over stormwater catch-pit inlets to be economically viable, stone and rubble and other large items, such as tins and bottles, must constitute a large proportion of the litter load. This is often the case in industrial areas and informal residential areas. Installation must be followed up with a regular sweeping programme (manual or mechanical), if it is not already in place, to remove the stone and rubble that will accumulate at the grids or else there is a risk of blockage and consequent flooding. Gratings may also delay the entry of plastic bags or large leaves into the stormwater system although ultimately these items tend to pass through or under the grid.

Gratings preventing objects larger than $50 \mathrm{~mm}$ in dimension entering the catch-pits were installed in Summer Greens and Montague Gardens in the spring of 2000. Summer Greens is a medium-density middle income residential area while Montague Gardens is a light industrial catchment. The grating was mounted on a hinge and could be lifted for cleaning purposes. Decreases in litter loads excluding sand of $45 \%$ (20 to $11 \mathrm{~kg} / \mathrm{ha} \cdot \mathrm{yr}$ ) and 74\% (86 to $22 \mathrm{~kg} /$ ha·yr) were noted in Summer Greens and Montague Gardens, respectively. An equivalent 2001 cost of R73/m for supply and installation assumed a compound increase of $10 \%$ per annum for the period 1999 to 2001. The annual cost of the grating was calculated assuming a 5-year design life, no scrap value and an interest rate of $15 \% / y r$. The cost of unit removal is dependent on the litter load which the grid prevents from entering the catch-pit. This is greater for Montague Gardens, so it is to be expected that the unit cost of litter reduction will be less. In actual fact, the figures worked out at R8.71/kg and R1.96/kg reduction for Summer Greens and Montague Gardens respectively. However, following installation, additional street sweeping would be required at an estimated cost of R11.56/ $\mathrm{kg}$. This cost must be added to give the effective cost $/ \mathrm{kg}$ reduction in litter reaching the stormwater system. The final cost of implementing this option was estimated at between R13.52/kg and R20.27/kg of litter removed from the stormwater system.

\section{Community education programmes}

Community education programmes are appropriate where there is a lack of environmental awareness and a high prevalence of littering behaviour. The programmes should be tailored to the particular target group.

In 2000 a Community Litter Management Project was implemented in Imizamo Yethu, a high-density, low-income, site-andservice residential settlement, by the Fairest Cape Association. Four educators were selected from the Community, trained by a coordinator from the Fairest Cape Association, and then employed full-time for a contract period of six months. The co-ordinator spent $1 \frac{1}{2}$ days a week on the project for its duration. A steering committee composed of the co-ordinator, the four educators, representatives from the South Peninsula Administration, and the Hout Bay Health Forum met on a monthly basis. The first phase (training and awareness) involved the educators joining the South Peninsula Administration's weekly cleaning rounds, clearing accumulated piles of rubbish away, and educating the residents about the collection system. The second phase of the Community Project tackled recycling with prizes awarded to residents who recycled the most items (SRK, 2000). From 2000 to 2001 a 32\% reduction or 19 $\mathrm{kg} / \mathrm{ha} \cdot \mathrm{yr}$ was measured in Imizamo Yethu. This may have been considerably greater as the baseline data from which it was calculated were not very reliable as some litter may have been lost. The cost of this programme was estimated at R326.70/ $\mathrm{kg}$ in the first year. Although the cost of this intervention seems expensive, the cost $/ \mathrm{kg}$ will fall if the reduction in litter loads is sustained without further intervention. In fact, if the reduction was sustained for two and a half years without any further intervention, the savings realised would exceed the cost of the programme.

In Ocean View, a high-density, low-income residential area with sub-economic housing and hostels, SRK Consulting Engineers facilitated a workshop for "Litter Management Strategy for Masiphumelele, Ocean View, Kommetjie and Imhoff's Gift” on behalf of the then Cape Metropolitan Council on 11 October 2000 (SRK, 2000). Subsequent to this, the public in Ocean View was sensitised to the litter problem through community meetings and clean-up campaigns involving the school children. There was a 35\% decrease in the amount of trapped litter excluding sand from 130 to $84 \mathrm{~kg} / \mathrm{ha} \cdot \mathrm{yr}$ in Ocean View in 2001 which can be attributed to this strategy.

\section{Grassing or hardening of verges}

Areas with unsurfaced road verges commonly have high sediment loads as a result of erosion of the road verge. Grassing these verges or hardening them considerably reduces erosion and sediment loads originating from the road verges. Unfortunately, hardening also increases flood peaks and facilitates the movement of pollutants, whilst grassing can only be considered for verges which have low pedestrian traffic and can be maintained and watered during the dry season.

In Ocean View, the level of cleansing service provided by the local administration was extended in 2001 to include the clearing of street verges which encouraged several residents to extend their gardening activities to these verges by planting and maintaining grass. There was a 52\% decrease in the amount of sand in Ocean View in 2001 which can be attributed to this strategy.

\section{The recommended selection procedure}

The above factors and litter management options are combined below in matrix form in Fig. 4 to simplify the selection of the most appropriate options. The process which should be followed is:

- Identify the factors which are relevant to the particular situation

- Select the most appropriate options by determining which options are associated as "generally effective” with the largest number of identified factors

The matrix does not provide a comprehensive list of all the available options for reducing litter loads entering the drainage system. However, it does provide a quick method for making a preliminary selection of appropriate litter management options for a given set of factors. The selected options should be investigated further and preferably implemented on a pilot basis in the area under consideration to determine their likely efficacy before proceeding with full implementation.

\section{Summary and conclusions}

The problem of urban litter in the drainage system can only be addressed in an effective and sustainable manner with integrated catchment management strategies composed of: 


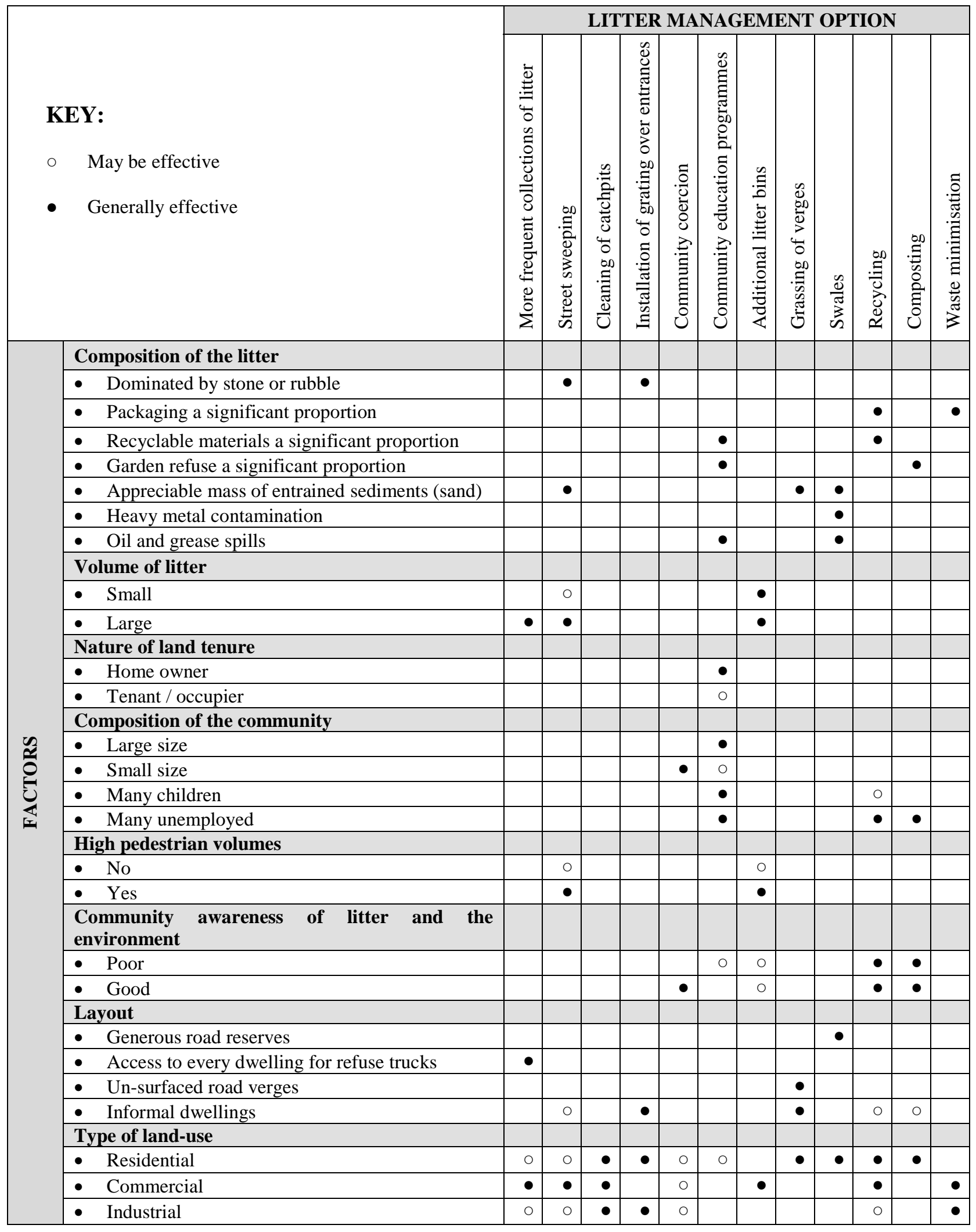

Figure 3

Selection matrix for litter management options 
- Planning controls,

- Source controls (reducing litter loads entering the drainage system) and

- Structural controls (removal of solid wastes from the drainage system).

These management strategies will require constant refinement based on data collected from ongoing monitoring. In selecting suitable strategies to address the litter problem the following two premises are fundamental:

- The composition of the litter varies with different land uses, income and service levels, and population densities

- The particular physical attributes of a catchment, the socioeconomic characteristics of its community and the level of services provided determine which litter management strategies are most likely to be effective in reducing the volume of litter entering the stormwater drainage systems.

The litter problem is a mix of technical and social issues which requires a multidisciplinary and not merely a purely technical approach. The establishment of partnerships between local government, NGOs and consultants can bring different skills and competencies to addressing the litter problem. Even with improved public awareness of litter and illegal dumping, however, structural controls to intercept litter such as traps and booms in streams will remain necessary.

\section{Acknowledgements}

The information contained in this paper emanates from a project cofunded by the WRC of South Africa and the then Cape Metropolitan Council (now part of the City of Cape Town). The project is fully described in a report published by the WRC (Marais and Armitage, 2003).

\section{References}

ANDRES D (1993) Synthesis of Highway Practice 184: Disposal of Roadside Litter Mixtures. National Cooperative Highway Research Program, Transportation Research Board, Washington DC.

ARMITAGE N (2001)The removal of urban litter from stormwater drainage systems. In: Larry W Mays (ed.) Stormwater Collection Systems Design Handbook. Chapter 19. McGraw Hill. 35 pp.

ARMITAGE N, ROOSEBOOM A, NEL C and TOWNSHEND P (1998) The Removal of Urban Litter from Stormwater Conduits and Streams. WRC Report No. TT 95/98. Pretoria.

ARMITAGE N and ROOSEBOOM A (2000a)The removal of urban litter from stormwater conduits and streams: Paper 1 - The Quantities involved and catchment litter management options. Water SA 26 (2) 181-187.

ARMITAGE N and ROOSEBOOM A (2000b)The removal of urban litter from stormwater conduits and streams: Paper 2 - Model studies of potential trapping structures. Water SA 26 (2) 189-194.

ARMITAGE N and ROOSEBOOM A (2000c) The removal of urban litter from stormwater conduits and streams: Paper 3 - Selecting the most suitable trap. Water SA 26 (2) 195-204.

AUSTRALIAN BUREAU OF STATISTICS (1999) Environmental Issues - People's Views and Practices in Australia. Canberra, Australia.

BARCLAY S (2002) Waste Minimisation Clubs: Facilitator's Manual: Summary and Outline Document. Pollution Research Group, University of Natal, Durban.
CANTERBURY URBAN RUNOFF TASKFORCE (1990) Catchment Management Study: Orissa St Stormwater Channel. Canterbury, NSW, Australia.

CAPE METROPOLITAN COUNCIL (1999) Cape Metropolitan Coastal Water Quality Committee Annual Report 1999. Cape Town.

CITY OF CAPE TOWN (2000) State of the Environment Report (SOE) for the City of Cape Town: Year 3 (2000). Cape Town.

CITY OF CAPE TOWN (2001) An Integrated Metropolitan Environmental Strategy for the City of Cape Town. Cape Town.

DEFRANCES CJ and TITUS RM (1994)The environment and residential burglary outcomes. Proc. Int. Seminar on Environmental Criminology and Crime Analysis. Coral Gables, Florida. 46-56.

DWAF (1999a) Managing the Water Quality Effects of Settlements: Volume 1: The National Strategy ( $1^{\text {st }}$ edn.). Pretoria.

DWAF (1999b) Managing the Water Quality Effects of Settlements: Volume 2: Guidelines for Implementation ( $1^{\text {st }}$ edn.). Pretoria.

DWAF (1999c) Managing the Water Quality Effects of Settlements: Volume 3: A Guide to Problem Analysis ( $1^{\text {st }}$ edn.). Pretoria.

DWAF (1999d) Managing the Water Quality Effects of Settlements: Volume 4: Instructors' Guide for Training Course ( $1^{\text {st }}$ edn.). Pretoria.

DWAF (1999e) Working Towards a Clean and Healthy Community. ( $1^{\text {st }}$ edn.). Pretoria.

FAIREST CAPE ASSOCIATION (2002a) Clean City Awards, Information Pamphlet and Entry/Nomination Form. Cape Town.

FAIREST CAPE ASSOCIATION (2002b) http://www.fairestcape.co/ $\mathrm{za} /$ (accessed 24 June 2002).

FLORIDA CENTER FOR SOLID AND HAZARDOUS WASTE MANAGEMENT (1998) The Florida Litter Study: 1998. Gainesville, Florida: Florida Center for Solid and Hazardous Waste Management.

HINSCH M (2000) Overcoming the pessimism that water quality impacts from urban areas cannot be solved - A light at the end of the tunnel. Proc. WISA, Bienn. Conf. and Exhibition. Sun City.

INSTITUTION OF MUNICIPAL ENGINEERING IN SOUTHERN AFRICA (2000) Collect-a-Can advertisement. IMIESA 25 (1) 60. Norwood, South Africa.

LIEBENBERG and STANDER (2002) Proposal to the City of Cape Town: A Communication Strategy for the MAC Campaign. Report by Liebenberg \& Stander Consulting Engineers, Cape Town.

MARAIS M and ARMITAGE N (2003) The Measurement and Reduction of Urban Litter Entering Stormwater Drainage Systems. WRC Report No. TT211/03. Pretoria.

NATIONAL CENTER FOR ENVIRONMENTAL DECISION-MAKING RESEARCH (1999) Decision Maker's Guide to Controlling Litter and Illegal Dumping. Washington.

PRESSEND M (1998) Strategies to Reduce Marine Litter through Land-Based Sources: An Assessment of Public Attitude and Awareness. M.Sc. (Conservation Biology) thesis, University of Cape Town.

SENIOR JC (1992) Litter control in urban waterways. Proc. Int. Symp. Urban Stormwater Management. Sydney. 234-239.

SKOGAN W (1990) Decline and Disorder: Crime and the Spiral of Decay in American Neighbourhoods. Free Press, New York.

SOUTH AFRICA (1996) The Constitution of the Republic of South Africa. Act 108 of 1996. Government Printers.

SRK (2000) South Peninsula Municipality: Litter Management Strategy for Masiphumelele, Ocean View, Kommetjie and Imhoff's Gift. Report No. 279987/1 by SRK Consulting Engineers, Cape Town.

VAN WYK JJ, MOODLEY P, BROWN SAP and VILJOEN P (2002) Water quality management in the new millennium: Towards a national water quality management framework policy for South Africa. Proc. WISA Bienn. Conf. and Exhibition. Durban.

VICTORIA STORMWATER COMMITTEE (1999) Urban Stormwater: Best Practice Environmental Management Guidelines. Collingwood VIC, Australia: CSIRO Publishing. 